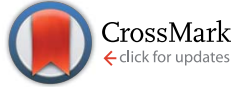

Cite this: RSC Adv., 2017, 7, 16319

Received 10th January 2017 Accepted 21st February 2017

DOI: $10.1039 / c 7 r a 00366 h$

rsc.li/rsc-advances

\section{An approach for correlating the structural and electrical properties of $\mathrm{Zr}^{4+}$-modified $\mathrm{SrBi}_{4} \mathrm{Ti}_{4} \mathrm{O}_{15} / \mathrm{SBT}$ ceramic}

\author{
Priyambada Nayak, ${ }^{\star a}$ Tanmaya Badapanda, ${ }^{\text {b }}$ Anil Kumar Singh ${ }^{\text {a }}$ \\ and Simanchalo Panigrahi ${ }^{a}$
}

In the present work, B-site modified layer-structured strontium bismuth titanate (SBT) ceramics with the nominal formula $\mathrm{SrBi}_{4} \mathrm{Ti}_{4-x} \mathrm{Zr}_{x} \mathrm{O}_{15}$ were prepared by solid state reaction route and the tailoring effects of zirconium $(\mathrm{Zr}$ ) were investigated thoroughly. The $\mathrm{X}$-ray diffraction analysis shows that the substitution leads to the formation of a single phase layered perovskite up to $x \leq 0.15$ and a $\mathrm{ZrO}_{2}$-based secondary phase was detected for higher $\mathrm{Zr}$-doped compositions. The higher grain-growth rate induced by the larger ionic radius of $\mathrm{Zr}^{4+}$ than $\mathrm{Ti}^{4+}$ was supported by the field emission scanning electron microscopy (FESEM) results. The transition temperature increases slightly for the $\mathrm{Zr}$-modified compositions, which can be described in terms of structural distortion due to the internal stresses developed within the ceramics. The Cole-Cole plot analysis of impedance spectra enabled to distinguish two relaxation behaviours that were assigned to originate from grains and grain boundaries. It was also observed that the remnant polarization and piezoelectric coefficient increases up to the solubility limit of $\mathrm{Zr}$ and then decreases with higher doping content. The temperature dependent piezoelectric coefficient was also studied, and was found to be stable up to the transition temperature in all compositions. All these results were explained on the basis of occupancy of the $\mathrm{Zr}^{4+}$ ion at the B-site and for the higher composition $\mathrm{ZrO}_{2}$ secondary phase. Even the composition $x=0.15$ exhibited low conductivity, a moderate dielectric constant and a highly stable $d_{33}$ value, demonstrating that the ceramic is an excellent material for hightemperature piezoelectric application. The possible reason for the enhancement of the electrical properties in the $\mathrm{Zr}$-modified ceramic was discussed based on the structural analysis, which may be used for designing and/or modifying properties of SBT-related ceramics.

\section{Introduction}

The layered perovskite family, including many titanates, has been extensively studied in recent years due to their remarkable electrical properties, which can be widely used for the manufacture of ferroelectric random-access memory and hightemperature piezoelectric sensors. ${ }^{\mathbf{1 , 2}}$ The structure of these compounds can be described as pseudo-perovskite $\left(\mathrm{A}_{m-1} \mathrm{~B}_{m^{-}}\right.$ $\left.\mathrm{O}_{3 m+1}\right)^{2-}$ slabs separated by $\left(\mathrm{Bi}_{2} \mathrm{O}_{2}\right)^{2+}$ layers along the crystallographic $c$-axis. ${ }^{3}$ The 12 -fold co-ordinated A-site can be occupied by mono-, di-, or tri-valent metallic cations, while the octahedral coordinated B-site can be occupied by tetra-, penta-, or hexa-valent metallic cations. The number of octahedral sites along the $c$-axis between two neighbouring $\left(\mathrm{Bi}_{2} \mathrm{O}_{2}\right)^{2+}$ layers is indicated by $m$. The origin of ferroelectricity in these ceramic

${ }^{a}$ Department of Physics and Astronomy, National Institute of Technology, Rourkela, Odisha-769008, India. E-mail: priyambada.pce@gmail.com; Fax: +91-661-2464723; Tel: $+91-9861260253$

${ }^{b}$ Department of Physics, C.V. Raman College of Engineering, Bhubaneswar, Odisha752054, India systems is the displacement of A-site cations of the perovskite block with cooperative tilting of the $\mathrm{BO}_{6}$ octahedra shown in Fig. 1(a). Among the layered family members, strontium bismuth titanate $\mathrm{SrBi}_{4} \mathrm{Ti}_{4} \mathrm{O}_{15}$ (SBT) is the most versatile; it presents a mobile unit in an orthorhombic structure, described by the $C_{12}^{2 v}\left(A 2_{1} \mathrm{am}\right)$ space group, exhibits unique properties, such as high Curie temperature $\left(\sim 530{ }^{\circ} \mathrm{C}\right)$, high dielectric constant ( $\sim 200$ at room temperature), high dielectric breakdown, low dielectric loss (0.017), high anisotropy and many other properties, suitable for use in acoustic and stress sensor devices working at high temperature.,5 However, compared with traditional piezoelectric ceramics, such as lead zirconate titanate (PZT) and $\mathrm{BaTiO}_{3}$, SBT has a low piezoelectric coefficient $(15 \mathrm{pC} / \mathrm{N})$ and electromechanical coupling factors with a high coercive field because the rotation of the spontaneous polarization is restricted to the $a-b$ plane. High electronic conductivity $\left(10^{5} \mathrm{~S} \mathrm{~cm}^{-1}\right)$ due to the volatilization of bismuth at high temperature should be attributed to defects mainly related to oxygen vacancies. Still, there has been increasing interest in SBT-doped systems because of the fact that their electrical properties can be controlled within a wide range by means of 

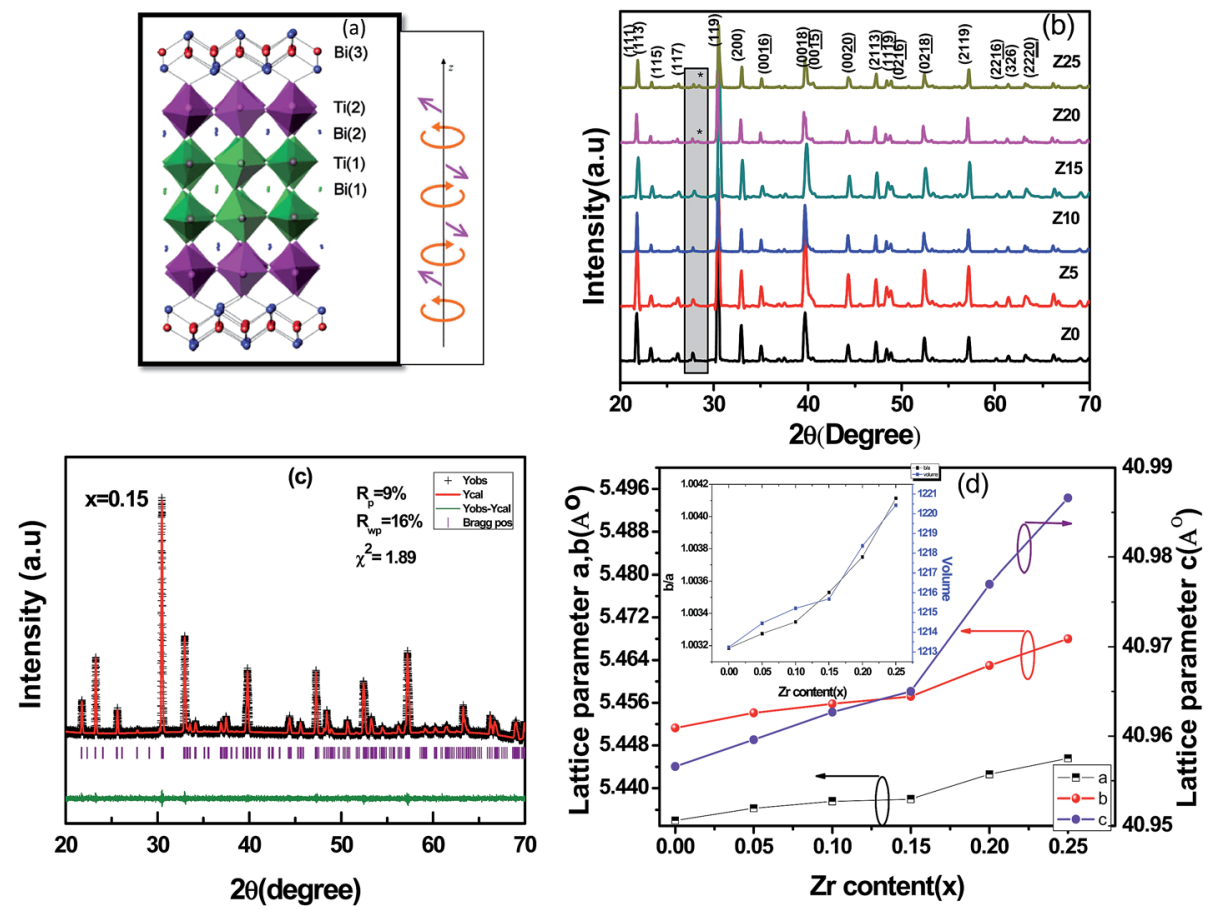

Fig. 1 (a) Crystal structure of SBT system. (b) XRD patterns of SBTZ- $x$ ceramics at RT. (c) Rietveld refinement of $x=0.15$ specimen. (d) Variation of lattice constants $(a-c)$ in SBTZ- $x$ ceramics.

mixed crystal formation and doping. For instance, partial replacement of Bi by other elements of the lanthanide series has been investigated systematically mainly in bulk ceramics. Properties of $\mathrm{La}^{3+}-$, $\mathrm{Dy}^{3+}$ - and $\mathrm{Er}^{3+}$-modified SBT ceramics, which lead to structural distortion, induced strain and significantly modifed electrical properties, were also reported by Chen et al., ${ }^{6}$ Mamatha et al. ${ }^{7}$ and Peng et al. ${ }^{8}$ At the same time, a decrease in the remnant polarisation $\left(P_{\mathrm{r}}\right)$ and Curie temperature $\left(T_{\mathrm{C}}\right)$ was reported due to the effect of foreign atoms at the Bi-site of SBT. Several reports are also available for A-, B- and both A- and B-site doped SBT, which have attracted surging attention owing to their enhancement of electrical properties. ${ }^{9,10}$ It has been reported that the ferroelectricity of the titanate-based layer perovskite structure, highly depends on the hybridization of the valence states between the O- ion and the Bsite ion, and which can be enhanced by the distortion of the $\mathrm{B}-\mathrm{O}$ interaction. Therefore, many reports are available on doping at the B-site of SBT ceramics, which tends to enhance the properties. However, modification at the B-site has mainly been focused on aliovalent cation doping, such as $\mathrm{V}^{5+}$ and $\mathrm{W}^{6+}$, as a substitution for $\mathrm{Ti}^{4+}{ }^{41,12}$ Moreover, it is noted that the aliovalent cations $\left(\mathrm{V}^{5+}\right.$ and $\left.\mathrm{W}^{6+}\right)$ will induce other additional space charges, and can decrease the oxygen vacancy considering the charge compensation mechanism. Consequently, studying the effect of B-site doping by cations with the same valence on the structural and electrical properties of SBT is interesting.

Recently, Ba $\left(\mathrm{Zr}_{x} \mathrm{Ti}_{1-x}\right) \mathrm{O}_{3}$ (BZT) has been choosen for the fabrication of ceramic capacitors because $\mathrm{Zr}^{4+}$ is chemically more stable than $\mathrm{Ti}^{4+}{ }^{43}$ Similarly, the detailed structural analysis of perovskites $\mathrm{Pb}\left(\mathrm{Zr}_{x} \mathrm{Ti}_{1-x}\right) \mathrm{O}_{3}(\mathrm{PZT})$ and BLSF ceramics such as $\mathrm{Bi}_{4} \mathrm{Ti}_{3} \mathrm{O}_{12}$ and $\mathrm{BaBi}_{4} \mathrm{Ti}_{4} \mathrm{O}_{15}$ has shown that the substitution of Ti by $\mathrm{Zr}^{4+}$ can make the material respond to the external field more easily. ${ }^{14-16}$ Hennings et al. suggested that incorporation of zirconia particles into barium titanate can form a core-shell structure and the desired temperature-stability of the dielectric properties is achieved by formation of core-shell grains. ${ }^{17}$ Jesurani et al. showed that the substitution of $\mathrm{Zr}$ in place of $\mathrm{Ti}$ causes fine-grained and dense microstructure, which changes the electrical properties of CCTO ceramics. ${ }^{18}$ It is well known that the inhomogeneous composition due to the doping element and internal stress within the microstructure are matters of concern because they greatly influence the electrical properties. Previous reports from the complex impedance plot of SBT analysis shows that two microelements, namely, bulk and grain boundary, contribute to the conduction process that affects the electrical properties. ${ }^{19}$ It has been argued that the plate-like grains are separated by a grain boundary formed along the low energy bismuth oxide layers and these grain boundaries are visible in the complex impedance plot. ${ }^{20} \mathrm{So}$, concerning all the factors, in the present work we report the effects of $\mathrm{Zr}^{4+}$ doping on the microstructure, ferroelectric, dielectric and piezoelectric properties of the SBT system. We believe that as $\mathrm{Zr}^{4+}$ possesses a different state (2d) than that of $\mathrm{Ti}^{4+}(3 \mathrm{~d})$ and the introduction of $\mathrm{Zr}^{4+}$ would bring in $\mathrm{Zr}-\mathrm{O}$ with a different valence band distance from that of Ti-O, it can lead to the enhancement of the electrical properties. We also investigate the grain and grain boundary effects on the electrical properties of Zr-doped SBT ceramics using complex impedance spectroscopy technique. 


\section{Experimental}

\subsection{Synthesis}

The Zr-modified SBT ceramics with general formula $\mathrm{SrBi}_{4}{ }^{-}$ $\mathrm{Ti}_{4-x} \mathrm{Zr}_{x} \mathrm{O}_{15}$ ((SBTZ) with $x=0.00,0.05,0.1,0.15,0.2$, and 0.25, named as Z05, Z10, Z15, Z20, and Z25, respectively) were fabricated by solid-state reaction route using high-purity (>99.9\%) oxides: $\mathrm{SrCO}_{3}, \mathrm{Bi}_{2} \mathrm{O}_{3}, \mathrm{TiO}_{2}$ and $\mathrm{ZrO}_{2}$. The powders were weighed in stoichiometric ratio and mixed thoroughly by ball milling in acetone medium for $24 \mathrm{~h}$. After the slurry was dried, the mixture was calcined at $900{ }^{\circ} \mathrm{C}$ for $3 \mathrm{~h}$ in a covered corundum crucible. The obtained powders were mixed with 3 wt\% binder (PVA) and compacted into disk-shaped pellets with diameter of $10.0 \mathrm{~mm}$ and thickness of $1.0 \mathrm{~mm}$ at $5 \mathrm{MPa}$. Finally, the pellets were sintered at $1050{ }^{\circ} \mathrm{C}$ for $2 \mathrm{~h}$ in a conventional furnace at a heating and cooling rate of $5{ }^{\circ} \mathrm{C} \mathrm{min}^{-1}$.

\subsection{Characterization}

The phase(s) of the final products were analysed by using X-ray diffraction (XRD) patterns collected by X-ray powder diffractometer (Rigaku Ultima IV) with $\mathrm{CuK}_{\alpha}$ radiation $(\lambda=1.5405 \AA)$ at a scanning rate of $2^{\circ} \min ^{-1}$ from $20^{\circ}$ to $80^{\circ}$. The surface morphology and micro-structural features of the sintered pellets were obtained using a field emission scanning electron microscope (JEOL\T-330). The density of the samples was measured by Archimedes' principle. The dielectric and impedance (frequency range $100 \mathrm{~Hz}$ to $1 \mathrm{MHz}$ ) data were collected using a Wayne Kerr impedance analyser, while keeping the electrode pellets in sandwich geometry. The electrical polarization of the poled samples was measured using ferroelectric loop-tracer (Radiant Technology). For the piezoelectric measurements, the samples were poled by DC electric field of 10 $\mathrm{kV} \mathrm{cm}{ }^{-1}$ for $30 \mathrm{~min}$ at $250{ }^{\circ} \mathrm{C}$ and the piezoelectric constant $d_{33}$ was measured using a YE2730A piezometer.

\section{Results and discussion}

\subsection{Structural characterization}

The room temperature X-ray diffraction (XRD) patterns of the SBTZ ceramics $(x=0.00-0.25)$ in the $2 \theta$ range of $20-70^{\circ}$ are shown in Fig. 1(b). As can be seen in Fig. 1(b), the Aurivillius structure was identified by indexing all the diffraction peaks on the basis of an orthorhombic cell with a space group $A 2{ }_{1} a m$ (JCPDS no. 43-0973), indicating that the $\mathrm{Zr}^{4+}$ ions diffused into the B-site lattice and formed solid solutions, as expected. Meanwhile, it is obvious that the highest diffraction peak in the SBTZ ceramics corresponds to the (119) orientation, which is consistent with the fact that it is the strongest diffraction peak in BLSFs with $m=4 .^{21-23}$ To confirm the purity of the layer perovskite phase, Rietveld refinement was carried out on the XRD data of the $x=0.15$ sample, as shown in Fig. 1(c). The final refinement convergence was achieved with $R_{\mathrm{p}}=9 \%, R_{\mathrm{wp}}=16 \%$ and $\chi^{2}=1.89$. However, a subtle crystallographic evolution of the SBTZ ceramics occurred along with the increasing Zr doping content $(x)$. Firstly, the average crystallite sizes for the samples increased with the increase of $\mathrm{Zr}$ content, as presented in
Table 1. The $\mathrm{Zr}^{4+}$ incorporation changed the type of bonding of $\mathrm{Ti}-\mathrm{O}$ to $\mathrm{Zr}-\mathrm{O}$, which may be the reason for changes in the crystallite size. Secondly, with the increase in doping concentration, the peaks at (119), (200) and (0016) are shifted towards lower $2 \theta$ values, which is expected because of the larger ionic radius of $\mathrm{Zr}^{4+}(0.72 \AA)$ as compared to $\mathrm{Ti}^{4+}(0.60 \AA)$. Thirdly, as marked in the XRD patterns, minor amounts of a secondary phase of $\mathrm{ZrO}_{2}$ were detected in the compositions with $x=0.2$ and 0.25 . Therefore, it is considered that the solid solubility limit is $\sim 0.15$. The shifting of the diffraction peaks with $\mathrm{Zr}^{4+}$ substitution indicates the change in the lattice parameters. Therefore, the subtle changes in these characteristic peaks illustrate a crystallographic evolution of the SBTZ ceramics, which can be described as the lattice distortion induced by the $\mathrm{Zr}^{4+}$ substitution for $\mathrm{Ti}^{4+}$.

In order to further investigate the effect of $\mathrm{Zr}$ doping on the crystallographic modification in the SBT system, the lattice parameters and cell volumes of the samples were calculated and are plotted as a function of doping content $(\mathrm{Zr})$, as shown in Fig. 1(d). It can be clearly seen that the crystallite size as well as lattice constants and unit cell volume $V$ increase monotonically with the increasing $x$, resulting in an expansion of the lattice constant. This expansion implies that the incorporation of $\mathrm{Zr}$ produces the lattice distortion in the pseudo-perovskite block. Therefore, the volume of the unit cell increased with substitution and the effect of $\mathrm{Zr}^{4+}$ substitution on orthorhombic distortion was evaluated by using the formula $2(a-b) /(a+b)$, which slightly increases with the increase in $\mathrm{Zr}$ content (Table 1 ). As the solid solubility limit of zirconia is $\leq 0.15$, there is a contradictory result of expansion of volume and crystallite size in the $x=0.2$ and 0.25 compositions. It may be because of the excess zirconia-containing phase present at the grain boundary of those ceramics. The sintered density, obtained by the Archimedes method, increased from 7.23 to $7.74 \mathrm{~g} \mathrm{~cm}^{-3}$ with increasing zirconium content up to $x=0.25$, indicating that the zirconium modifications enhanced the densification of the SBT ceramics. Related to the theoretical density $\left(\rho=7.99 \mathrm{~g} \mathrm{~cm}^{-3}\right.$, derived from JCPDS 43-0973 and X-ray diffraction), the percentages of the theoretical densities ' $\rho$ ' of the unmodified and zirconium-modified SBT ceramics were obtained, and are listed in Table 1 . The $\rho$ of the zirconium-modified SBT ceramics were higher than $96 \%$ of the theoretical density, indicating acceptable densification during the sintering process.

\subsection{Raman analysis}

Raman spectroscopy was used to probe the subtle changes in the local structure of the modified system under investigation, which can be correlated with the structural study performed by $\mathrm{X}$-ray diffraction. The room temperature Raman spectra of the Zr modified SBT ceramics from $100-1200 \mathrm{~cm}^{-1}$ are shown in Fig. 2. It is reported that SBT ceramics have around seven Raman active modes. ${ }^{24}$ In order to determine the exact peak frequencies of the different Raman active modes, we fitted the Raman data of the unmodified SBT with the sum of seven peaks by Gaussian fit, which is inserted in Fig. 2. The thin solid lines shown in the fitted graph are of the individual modes and the 
Table 1 Parameters obtained from the structural and dielectric properties of Zr modified SBT ceramic

\begin{tabular}{|c|c|c|c|c|c|c|c|c|}
\hline Compound & $\begin{array}{l}\text { Measured density } \\
\left(\mathrm{g} \mathrm{cm}^{-3}\right)\end{array}$ & $\begin{array}{l}\text { Percentage of } \\
\text { theoretical density }\end{array}$ & $\begin{array}{l}\text { Orthorhombicity } \\
{[2(a-b) /(a+b)]}\end{array}$ & $\begin{array}{l}\text { Tetragonality, } \\
c / a\end{array}$ & $\begin{array}{l}\text { Particle size } \\
\text { (§) }\end{array}$ & $\begin{array}{l}\text { Grain size } \\
(\mu \mathrm{m})\end{array}$ & $\begin{array}{l}\varepsilon_{\mathrm{r}} \\
\text { at } 100 \mathrm{kHz}\end{array}$ & $T_{\mathrm{C}}\left({ }^{\circ} \mathrm{C}\right)$ \\
\hline$x=0.00$ & 7.23 & 90.48 & 3.1 & 7.5370 & 447 & 2.549 & 1573 & 535 \\
\hline$x=0.1$ & 7.51 & 93.99 & 3.3 & 7.5332 & 495 & 3.776 & 1706 & 537 \\
\hline$x=0.15$ & 7.68 & 96.12 & 3.5 & 7.5332 & 512 & 4.653 & 1835 & 537 \\
\hline$x=0.2$ & 7.7 & 96.37 & 3.7 & 7.5288 & 525 & 4.969 & 1130 & 555 \\
\hline
\end{tabular}

thick solid line shows the total fit to the experimental data (open circle). In the undoped SBT system, vibrational modes were observed due to the presence of the referred type of Ti-O, $\mathrm{Bi}-\mathrm{O}, \mathrm{Sr}-\mathrm{O}$ bond. It can be seen from the figure that the Raman spectra of all specimens exhibit the same phonon modes at approximately $158,272,340,449,563,749$ and $868 \mathrm{~cm}^{-1}$, which are related to the orthorhombic phase $\left(A 2_{1} \text { am space group }\right)^{25,26}$ The low frequency vibrational modes are ascribed to the $\mathrm{Bi}^{3+}$ ion at the A-site, generally occurring in the range below $200 \mathrm{~cm}^{-1}$. The vibrational mode at $158 \mathrm{~cm}^{-1}$ is the characteristic feature of the layered structures and corresponds to the vibrations as a whole. The vibrational modes related to the $\mathrm{Ti}-\mathrm{O}$ bonds are located at wave numbers beyond $200 \mathrm{~cm}^{-1}$ (272, 563 and 749 $\mathrm{cm}^{-1}$ ). The mode at $272 \mathrm{~cm}^{-1}$ corresponds to the torsional bending of the $\mathrm{TiO}_{6}$ octahedra, which is because of $\mathrm{B}_{1 \mathrm{~g}}$ mode, and the modes at 563 and $749 \mathrm{~cm}^{-1}$ correspond to the $\mathrm{TiO}_{6}$ stretching mode, which corresponds to $\mathrm{B}_{2 \mathrm{~g}}$ and $\mathrm{B}_{3 \mathrm{~g}}$ modes. ${ }^{12}$ The mode at $868 \mathrm{~cm}^{-1}$ is probably ascribed to the vibrations of the A-O bond. ${ }^{25}$ Compared with the Raman spectra of the SBT ceramic system, it is observed that the modes at 272,563 and $749 \mathrm{~cm}^{-1}$ remain undeviated up to $x \leq 0.15$. For higher concentrations, a clear downshift and peak broadening was observed with increasing $\mathrm{Zr}$ content. The anisotropic crystal structure of SBT where the $c$-lattice parameter is significantly larger than the in-plane lattice parameters $a$ and $b$, ensures that

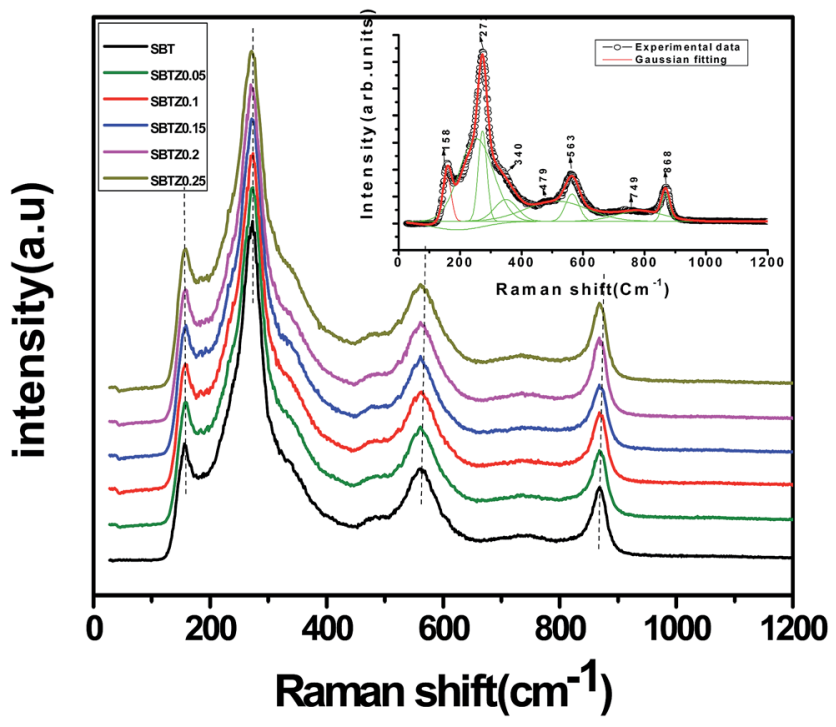

Fig. 2 Raman spectra of SBTZ-x ceramics at room temperature. the $x-y$ vibrations of the Ti atoms are affected much more strongly by the size of the substitutive atom as compared to the $z$-axis vibrations. This explains the shifting of the mode that corresponds to the $x-y$ vibration of apical oxygen atoms of $\mathrm{TiO}_{6}$ octahedra towards the lower frequency. The large shift in the $\mathrm{Z} 20$ and Z25 compositions seems to originate from the ionic difference between the $\mathrm{Ti}$ and $\mathrm{Zr}$ atoms, which alters the environment around the $\mathrm{TiO}_{6}$ octahedra in an anisotropic manner.

\subsection{Microstructural analysis}

The FESEM micrographs of the SBTZ sintered samples are shown in Fig. 3. The micro-structure reveals tightly bonded welldefined grains with no obvious porosity, corresponding to the high relative density of up to $96 \%$ discussed in the previous section. The grain sizes were measured by linear intercept method and are listed in Table 1. The average length of the plate-like grains significantly increased from $2.549 \mu \mathrm{m}$ to 5.308 $\mu \mathrm{m}$, but the thickness varies from $0.50 \mu \mathrm{m}$ to $0.38 \mu \mathrm{m}$ for pure SBT and SBTZ25 ceramics, respectively. This shows that the aspect ratio $L / T$ (length/thickness) is controlled by the $\mathrm{Zr}$ dopants. The $\mathrm{Zr}$ modifications increase the grain growth rate in the direction perpendicular to the $c$-axis and result in the highly anisotropic microstructure of the SBTZ-25 ceramic. The increase in grain size with $\mathrm{Zr}^{4+}$ substitutions seems to be related to the higher grain-growth rate induced by the larger ionic radius of $\mathrm{Zr}$ than $\mathrm{Ti}^{27}$

\subsection{Dielectric study}

Fig. 4 illustrates the frequency dependence of the real $\left(\varepsilon^{\prime}\right)$ and imaginary part dielectric constant $\left(\varepsilon^{\prime \prime}\right)$ of all the ceramics at $600{ }^{\circ} \mathrm{C}$. The dielectric constants for all the samples show dispersion at lower frequencies and become constant at higher frequencies. This behaviour may be explained on the basis of Maxwell Wagner type interfacial polarization in agreement with Koop's theory. ${ }^{28}$ According to this model, polycrystalline ceramics have a heterogeneous microstructure that can be imagined to consist of semiconducting grains separated by insulating grain boundaries, also depicted in the Nyquist plots (discussed later). Free charges build up owing to the defects; that is, oxygen vacancies present in the sample create space charges at the interface between the sample and the electrode's space-charge polarization, whose polarization responds to the applied electric field. At low frequencies these charges have enough time to move longer distances in the sample, creating larger electronic polarization and therefore a high value of 


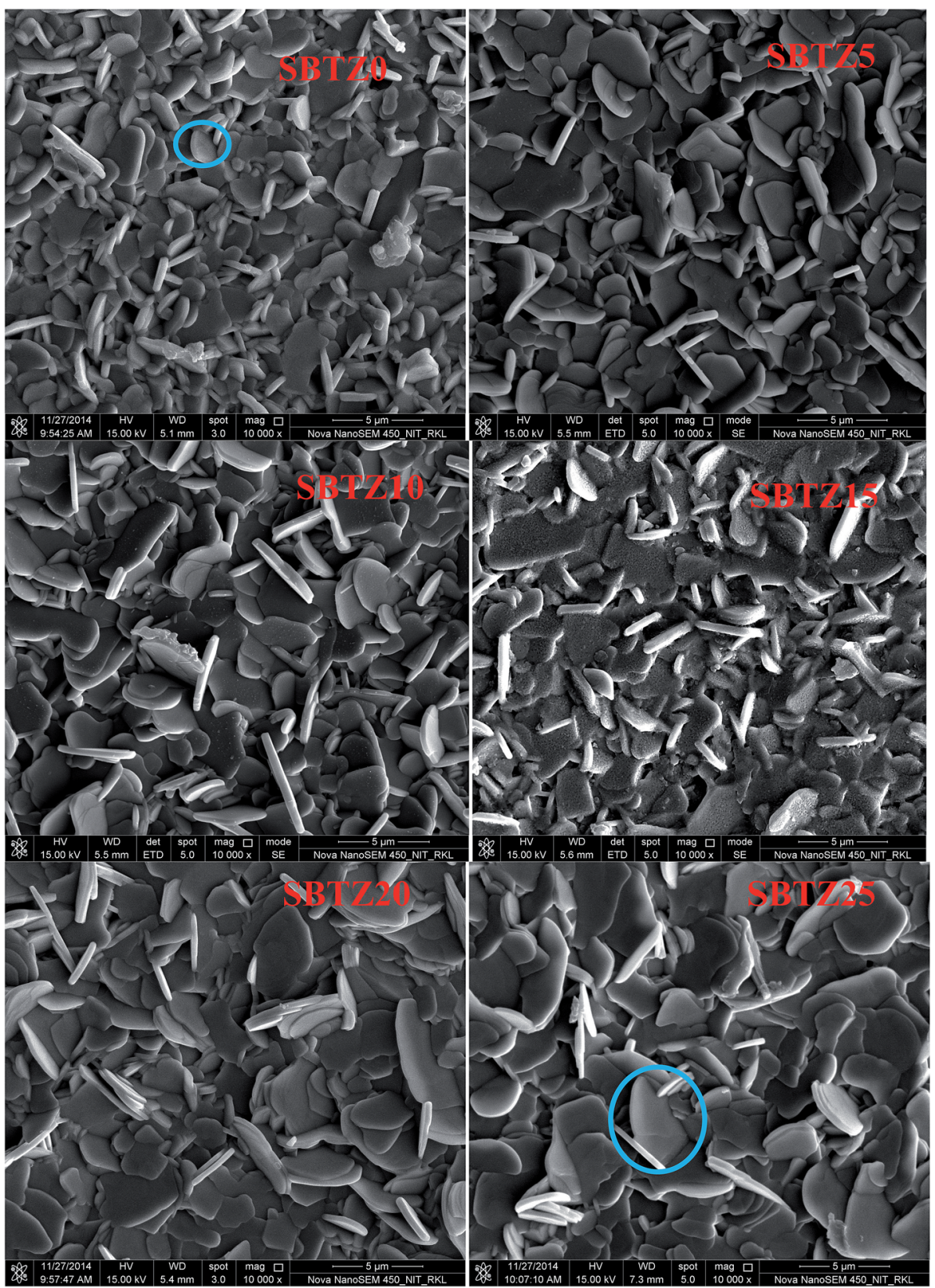

Fig. 3 FESEM image of SBTZ-x ceramic system.

dielectric constant. As the frequency increases, the charge carriers are unable to follow the applied external field and so there is a decrease in polarizability. On the other hand, it has been observed that the value of $\varepsilon^{\prime}$ was found to increase up to $x$ $=0.15$. In a grain boundary barrier layer system, the dielectric constant of the materials is linearly proportional to the average value of grain size and inversely proportional to the grain boundary thickness. ${ }^{29}$ As the grain size increases due to $\mathrm{Zr}$ doping, so the dielectric constant increases up to $x=0.15$. However, for higher values of $x$, the grain boundary thickness increases due to the presence of the secondary phase, which reduces the dielectric constant.

The insert of Fig. 4 shows variation of loss factor $\left(\varepsilon^{\prime \prime}\right)$ with frequency. The loss factor $\left(\varepsilon^{\prime \prime}\right)$ decreases continuously with increasing frequency. As grain boundaries have high resistance, more energy is required for the motion of charge carriers in the low frequency region, hence the energy loss is high. Conversely, less energy is required for the motion of charge carriers in the high frequency region due to the lower resistance, which reduces the loss. It can also be observed from the figure that the dielectric loss decreases with increasing $\mathrm{Zr}$ substitution up to $x$ $=15$ then increases with further doping. The increment in the dielectric loss at higher doping may be attributed to the poor electric insulation of the impurity phases. ${ }^{30}$

To further elucidate the temperature-dependent dielectric properties, the relative permittivity $\left(\varepsilon_{\mathrm{r}}\right)$ and dielectric loss $(\tan \delta)$ at $100 \mathrm{kHz}$ frequency as a function of temperature are presented in Fig. 5. The phase transition in the present modification (from 


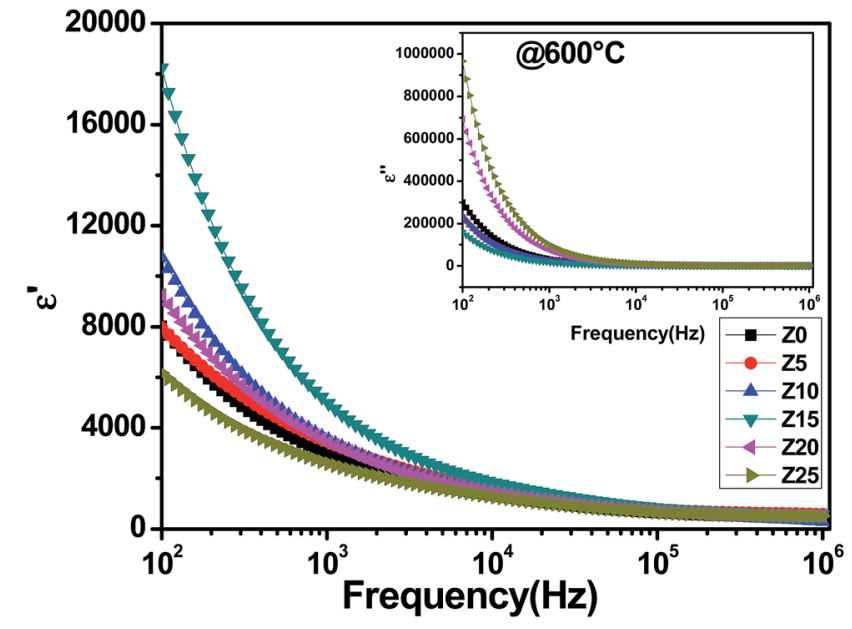

Fig. 4 Frequency dependence of the real $\left(\varepsilon^{\prime}\right)$ and imaginary parts of the permittivity $\left(\varepsilon^{\prime \prime}\right)$ of SBT and the modified system at $600{ }^{\circ} \mathrm{C}$.

Fig. 5(a)) is slightly higher than that of SBT $\left(T_{\mathrm{C}}=\sim 530^{\circ} \mathrm{C}\right)$ and the variation is within $25^{\circ}$ (listed in Table 1 ). In BLSF ceramics, isovalent substitution at the B-site changes the lattice distortion. The structural distortion is explained in terms of a lattice mismatch between the $\mathrm{BO}_{2}$ and $\mathrm{AO}$ planes in the perovskite-
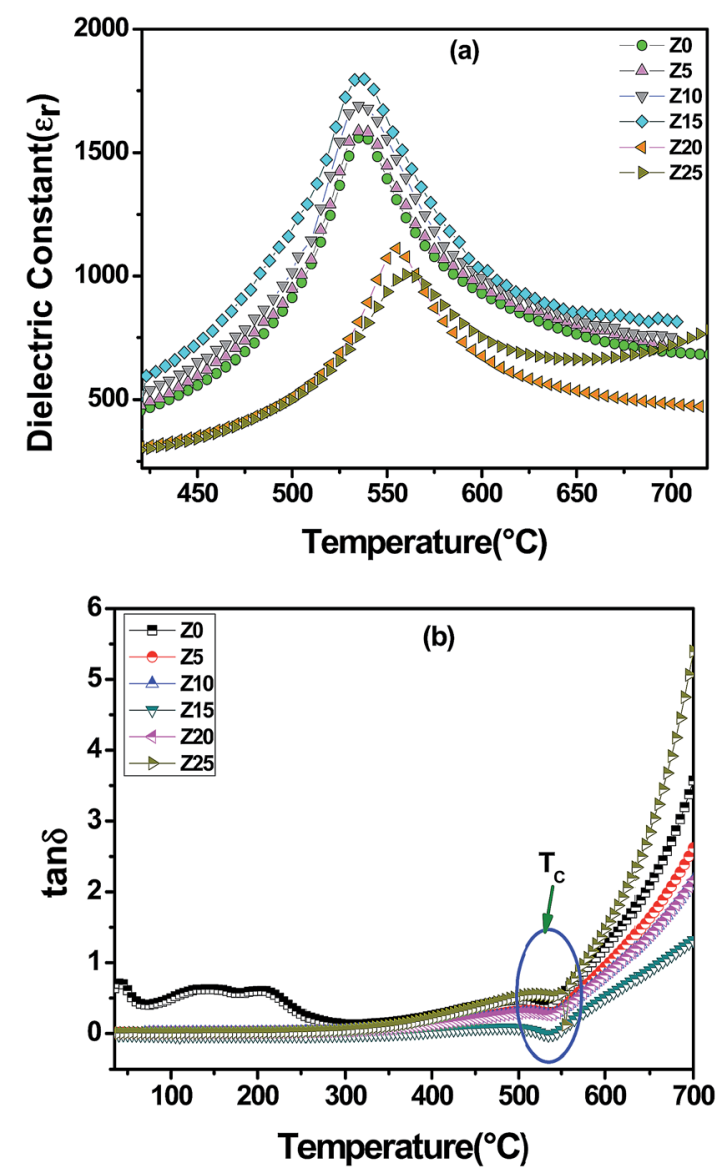

Fig. 5 (a) Temperature dependence of dielectric constant $\left(\varepsilon_{\mathrm{r}}\right)$. (b) Dielectric loss $(\tan \delta$ ) of SBTZ-x ceramic at frequency of $100 \mathrm{kHz}$. type unit, and the tolerance factor $(t)$ of the perovskite-layer units is given by:

$$
t=\frac{r_{\mathrm{A}}+r_{\mathrm{B}}}{\sqrt{2}\left(r_{\mathrm{B}}+r_{\mathrm{O}}\right)}
$$

where $r_{\mathrm{A}}, r_{\mathrm{B}}$, and $r_{\mathrm{O}}$ are the ionic radii of an A-site cation, a B-site cation, and an oxygen ion, respectively. A decrease in ' $t$ ' results from the B-site substitution with larger size $\mathrm{Zr} / \mathrm{Ti}$ (0.72 ̊, $0.60 \AA$ for $6 \mathrm{CN})$. This coincides with the results of the XRD patterns and earlier reports. ${ }^{16,31}$

The variation of loss tangent $(\tan \delta)$ as a function of temperature is given in Fig. 5(b). The dielectric loss $(\tan \delta)$ for zirconium-modified SBT ceramics was found to be more stable than that of the unmodified SBT samples. The figure shows a kink, observed in all the ceramics, which separates the ferroelectric and paraelectric phase transition mechanisms. This kind of sharp peak occurs when the hopping frequency of the electric charge carriers becomes approximately equal to that of the external applied AC electric field. ${ }^{32}$

\subsection{Relaxation behaviour and electrical properties}

The impedance spectroscopy method is widely used to characterize the electrical properties of materials and give us data regarding both the resistive (real part i.e. $Z^{\prime}=Z \cos \theta$ ) and reactive (imaginary part i.e. $Z^{\prime \prime}=-Z \sin \theta$ ) components with various transport mechanisms operating within the microstructure of the material. The Cole-Cole plots (Nyquist plots) of SBTZ samples plotted at various temperatures are shown in Fig. 6. The low temperature plots become straight lines with a large slope, indicating the high insulating nature, whereas with increasing temperature, the curves bow toward the abscissa axes to form semi-circular arcs observed in all samples. Further, at higher temperature the radii of the semi-circular arcs become smaller, indicating lower values of resistance. The semi-circular arcs show a slight distortion, indicating deviation from the Debye relaxation mechanism, which may be due to the presence of multi-relaxation processes in the material. The inset of Fig. 6 (for $x=0.00$ ) shows the Bode-phase diagram with frequency for the $\mathrm{Z} 0$ ceramic as a representative curve. The arrows show steplike changes in the curves, which suggests that there are at least two relaxation behaviours in the ceramics. But to make it more clear about the relaxation process, the complex impedance data were simulated with an equivalent circuit as inserted in Fig. $6(x$ $=0.00$ ) using 'ZSimpWin' software. The equivalent circuit contains two resistors in series, each shunted by a constant phase element (CPE). The impedance of CPE given by Abram et al. $^{33}$ is:

$$
Z_{\mathrm{Q}}^{*}=\frac{1}{(i \omega)^{n} C}
$$

where ' $n$ ' is the frequency independent parameter of Jonscher's power law and its value varies from 0 to 1 ; for an ideal capacitor $n=1$ and for an ideal resistor it is 0 . The simulations fitted well with the experimental data and showed that are two relaxation mechanism in the present samples. The first semi-circular arc at higher frequency is related to the grain while the second 

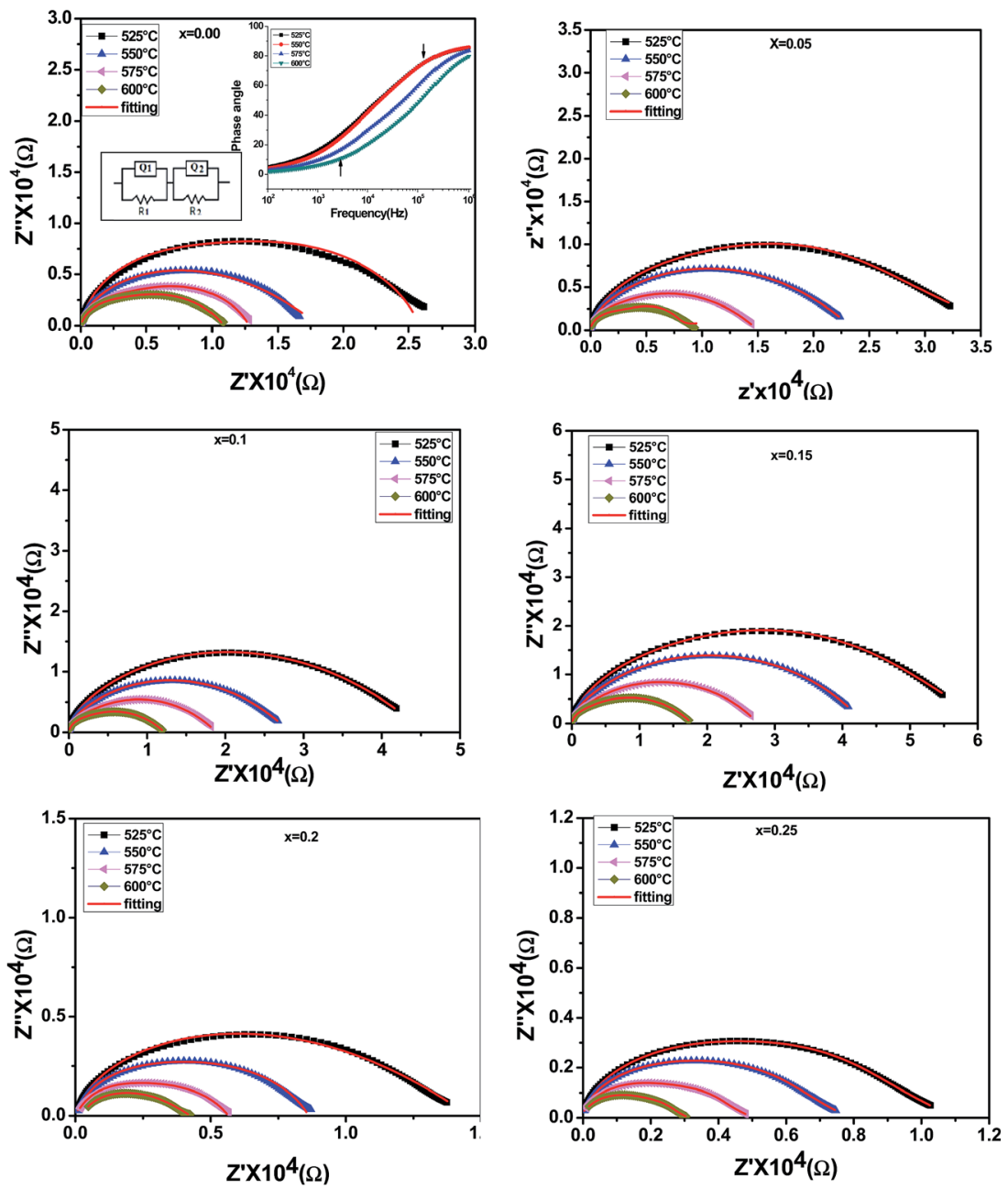

Fig. 6 The Nyquist plots for $\mathrm{Zr}$-doped SBT ceramics at temperatures of $525-600^{\circ} \mathrm{C}$.

semi-circular arc at lower frequency is related to the grain boundary. The fitting parameters $R, C$ and $n$ both for grain boundaries $\left(R_{\mathrm{gb}}, C_{\mathrm{gb}}, n_{\mathrm{gb}}\right)$ and grains $\left(R_{\mathrm{g}}, C_{\mathrm{g}}, n_{\mathrm{g}}\right)$ are listed in Table 2. From the fitting parameters it is observed that the grain and grain boundary resistances for all the SBTZ composition exhibit decreasing trends with the increase in temperature. It indicates that the conductivity increases with increasing temperature in all compsoitions, exhibiting the typical negative temperature coefficient of resistance (i.e., NTCR) behaviour usually observed in semiconductors. It was also observed that the grains are more resistive than the grain boundary in all the samples. Grain and grain boundary resistance increases with increases in $\mathrm{Zr}^{4+}$ content up to $x=0.15$, then after it decreases, indicating a decrease in conductivity of the samples. The higher conductivity in $\mathrm{Z} 20$ and $\mathrm{Z} 25$ samples may be related to the $\mathrm{ZrO}_{2}$ secondary phase as detected from XRD.

The variation of the imaginary part of impedance $\left(Z^{\prime \prime}\right)$ with frequency for SBTZ ceramics at various temperatures is shown in Fig. 7. It can be observed from the figure that all the curves merge at a frequency greater than $100 \mathrm{kHz}$. This is owing to the fact that at higher frequencies the dispersion due to grains dominates and the space charge effect decreases. It is also observed that the peak in each graph shifts towards higher frequency and the magnitude of the peak decreases as the temperature is raised. This can be ascribed to the temperature dependent relaxation process in the samples and the peaks broaden with rise in temperature due to multiple relaxations in the samples. The maximum value of the imaginary part of impedance $\left(Z^{\prime \prime}{ }_{\text {max }}\right)$ increases with increasing $\mathrm{Zr}$ concentration up to $x \leq 0.15$ and for higher concentrations it decreases. This is in well agreement with the interpretation of the conductivity results presented in the next section. Relaxation time $(t)$ is calculated from the peak position of $Z^{\prime \prime}{ }_{\text {max }} v s$. frequency plots using the relation $2 \pi f_{\max } \tau=1$, where $f_{\max }$ is the relaxation frequency. The variation of relaxation time with the inverse of temperature is presented in Fig. 8. The activation energy is calculated from the linear fit to the slope of the curve based on the equation:

$$
\tau=\tau_{0} \exp \left(-E_{\mathrm{a}} / k_{\mathrm{B}} T\right)
$$

where $E_{\mathrm{a}}$ is the activation energy, $k_{\mathrm{B}}$ is the Boltzmann constant, and $T$ is the absolute temperature. The calculated activation energies are listed in Table 2 . The activation energy increases with $\mathrm{Zr}^{4+}$ content and reaches a maximum at $x=0.15$. This 
Table 2 Comparison of electrical properties for SBTZ ceramics: $E_{\mathrm{a}}$ : activation energy, $P_{\mathrm{r}}$ : remnant polarization, $d_{33}$ : piezoelectric constant

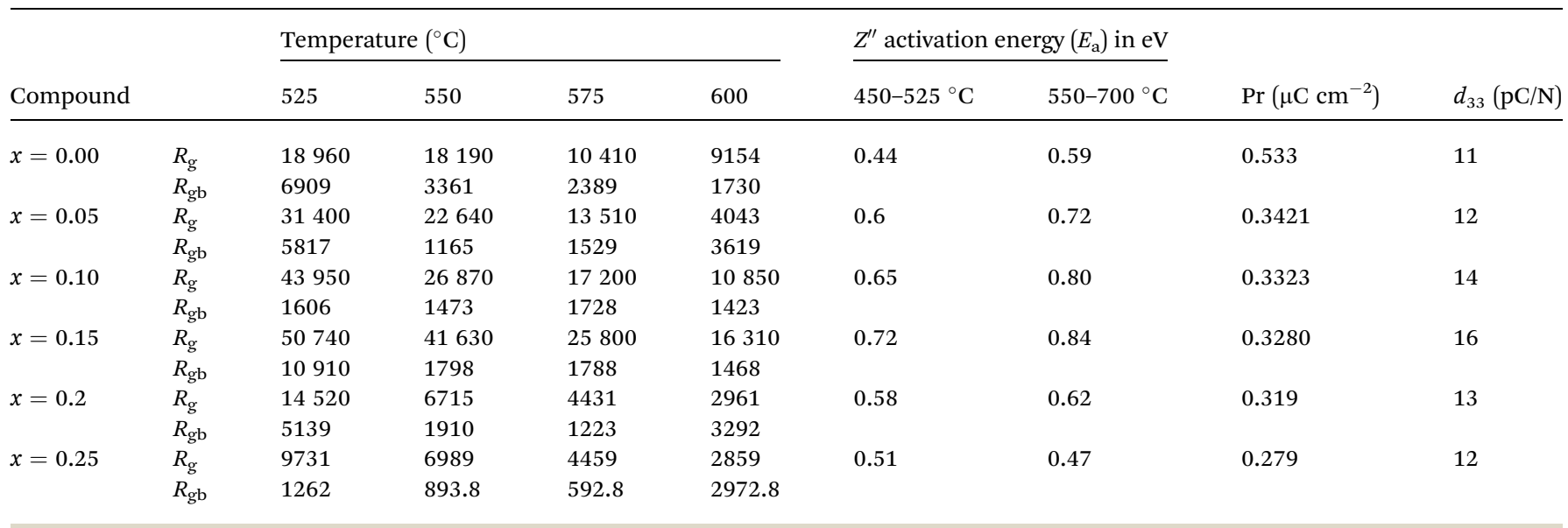

increase in activation energy may be due to the decrease in the concentration of oxygen vacancies of the system. Furthermore, the replacement of $\mathrm{Ti}^{4+}$ by $\mathrm{Zr}^{4+}$ reduced the probability of hopping between the $\mathrm{Ti}^{4+}$ and $\mathrm{Ti}^{3+}$ states. Hence, as the hopping probability between the two titanium states decreases in the present case, a decrease occurred in the concentration of charge carriers, which increases the activation energy. ${ }^{34,35}$ However, the Z20 and Z25 samples possessed a secondary phase, mainly $\mathrm{ZrO}_{2}$, which contributes to increasing the loss of the system and hence decreasing $E_{\mathrm{a}}$.

\subsection{Conduction mechanism}

In order to understand the transport behaviour of the modified system, the samples were further characterized by frequency and temperature dependence of AC conductivity. Fig. 9(a) depicts the variation of $\mathrm{AC}$ conductivity $\left(\sigma_{\mathrm{ac}}\right)$ with frequency for all

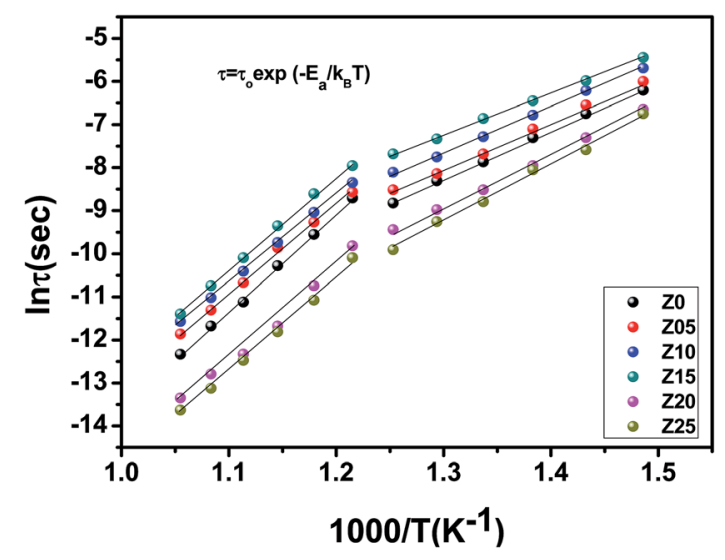

Fig. 8 The variation of $\ln \tau$ vs. 1000/T (Arrhenius plot) with the imaginary impedance $\left(Z^{\prime \prime}\right)$ of SBTZ ceramic.
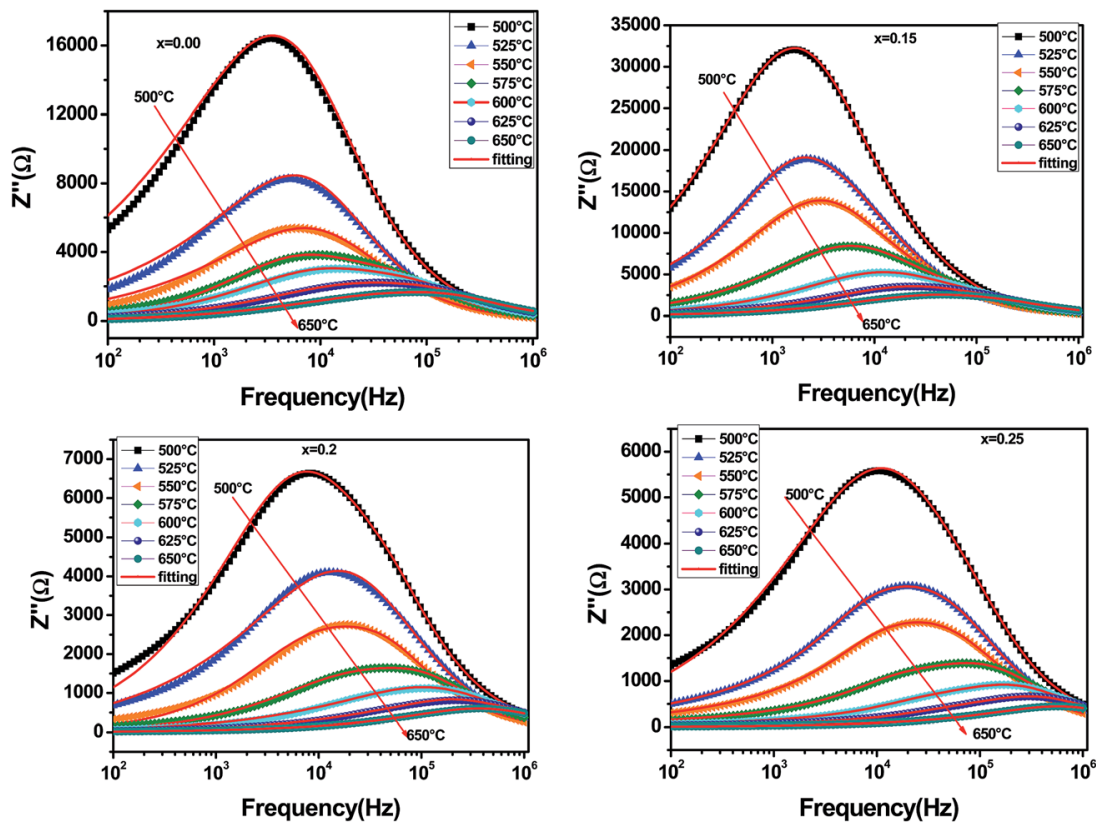

Fig. 7 Frequency dependence of the imaginary part of impedance $\left(Z^{\prime \prime}\right)$ for SBT and the modified systems at selected temperatures. 
the compositions at $600{ }^{\circ} \mathrm{C}$. It is observed that the $\mathrm{Zr}$ substitution reduces the conductivity up to $x \leq 0.15$, then increases with further increases in doping content (in the Z20 and Z25 ceramic systems). In the SBT system, the conduction mechanism of the leakage current involves (a) a space charge-limited conduction related to oxygen vacancies and (b) a field-assisted ionic conduction related polaron hopping between $\mathrm{Ti}^{4+}$ and $\mathrm{Ti}^{3+} \cdot{ }^{36}$ Hence the reason behind lowering the conductivity of the sample with $\mathrm{Zr}$ doping may be attributed to the lowering of the $\mathrm{Ti}^{4+}$ concentration by $\mathrm{Zr}^{4+}$ substitution, or it can be described by the incorporation of $\mathrm{Zr}^{4+}$ with larger ionic radius may bring in a large distortion of $\mathrm{TiO}_{6}$. Nevertheless, when the $\mathrm{Zr}^{4+}$ doping content is modified to $>15 \mathrm{~mol} \%$, the extra zirconia containing phase occurs at the grain boundary, related to the impurity phase and decreased electrical insulation. From the Cole-Cole plot at $600{ }^{\circ} \mathrm{C}$ for $\mathrm{Z} 20$ and Z25 samples, we showed that the grain contribution effect decreases and the grain boundary contribution effect increases. This may be owing to an increase in the grain boundary volume and a proportionate increase in disorder introduced into the sample, which supports the conductivity data.

We studied the temperature dependence of the AC conductivity behaviour for all compositions, but a representative plot of the conductivity spectrum of the Z15 system at a few selected temperatures is shown in Fig. 9 (b). The total conductivity is simulated by Jonscher's power law ${ }^{37}$ and is given as

$$
\sigma_{\mathrm{ac}}=\sigma_{\mathrm{dc}}+A \omega^{n}
$$

where $\sigma_{\mathrm{dc}}$ is the bulk DC conductivity and $A$ is the pre-factor, which depends on the temperature and composition, and determines the strength of the polarizability. The quantity ' $n$ ' is the dimensionless frequency exponent lying between 0 and 1 , which represents the degree of interaction between mobile ions with the lattice around them. The variation of the frequency exponent $(n)$ with temperature is inserted in Fig. 9(b). It is observed that, the parameter $n$ first increases, gradually attains a minimum value at a particular temperature and subsequently increases with further increases in temperature. The minimum value of ' $n$ ' confirms the transition temperature $\left(T_{\mathrm{C}}\right)$, which shows that there is a maximum interaction between the charge carriers at $T_{\mathrm{C}}$. The values of ' $n$ ' are less than one, confirming the non-Debye behaviour of the sample. Meanwhile, the motion of the charge carriers takes a translational motion with a sudden hopping. Different hopping mechanisms have been reported by different researchers, who predicted different temperature and frequency dependencies of the exponent $n .^{38}$ The cations surrounded by close packed oxygen ions can be considered as isolated from each other for the minute overlap of the charge clouds, which results in the formation of the polarons, and the charge transport may be considered between the nearest neighbours of $\mathrm{Ti}^{3+}$ and $\mathrm{Ti}^{4+}$.

In the case of small polaron (the self-trapped electronic charge with spatial extension comparable to one unit cell) hopping, $n$ increases with temperature (Region II), while for large polaron (spatial extension of charged quasi particle comparable to several unit cells) hopping, $n$ decreases with increasing temperature (Region I). ${ }^{38,39}$ According to the small polaron model, the small polaron wells of two sites overlap, which reduces the polaron hopping energy after Zr modification. ${ }^{\mathbf{4 0}}$ This fact indicates that the conductivity in this sample form may be assured by the small polaron hopping conduction at high temperature.

In order to provide the ions that are responsible for the mechanism of conduction in this material, we looked into the
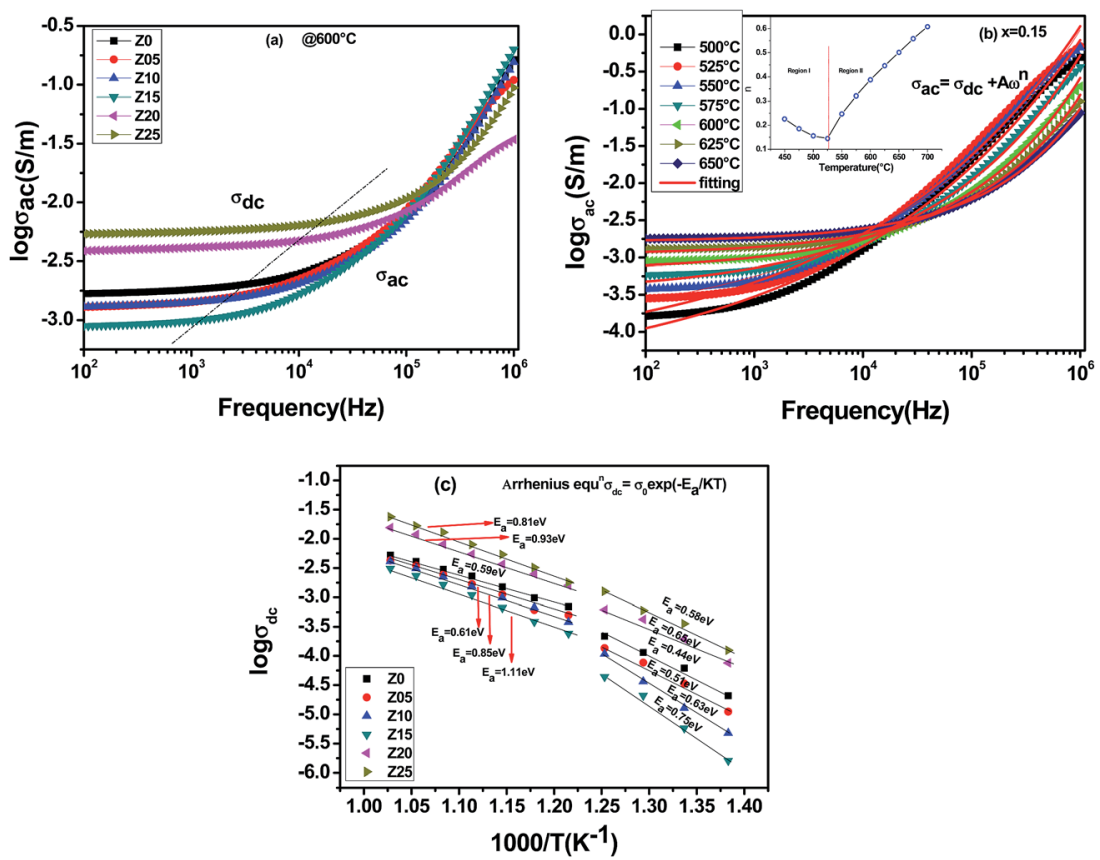

Fig. 9 (a) Frequency dependency of the AC conductivity of SBTZ ceramics at $600^{\circ} \mathrm{C}$. (b) Variation of AC conductivity with frequency at different temperatures for $x=0.15$ ceramic. (c) Temperature dependence of the DC conductivity $\left(\sigma_{\mathrm{dc}}\right)$ of SBTZ ceramics. 
structural arrangement. For bismuth layer-structured compounds, the $\left(\mathrm{A}_{n-1} \mathrm{~B}_{n} \mathrm{O}_{3 n+1}\right)^{2-}$ slabs and the $\left(\mathrm{Bi}_{2} \mathrm{O}_{2}\right)^{2+}$ slabs along the $c$ axis are connected by the strong $\mathrm{Bi}-\mathrm{O}$ bond. The $\mathrm{Zr}$ ions was observed to preferably occupy the Ti site of the perovskite layers, as depicted in Fig. 1(a). The substitution of larger $\mathrm{Zr}$ ions induces stronger structural distortion by the shortest $\mathrm{Bi}-\mathrm{O}$ bond lengths and the buckling of $\mathrm{Ti}-\mathrm{O}$ oxygen octahedrons. It is accepted that the strong structural distortion in SBTZ results from the expected larger interstrain between the perovskite blocks and $\mathrm{Bi}_{2} \mathrm{O}_{2}$ slabs. The compressive stress on the perovskite blocks would drive the larger $\mathrm{Zr}$ ions away from the oxygen octahedrons adjacent to the $\mathrm{Bi}_{2} \mathrm{O}_{2}$ slabs.

The variation of DC conductivity $\left(\log \sigma_{\mathrm{dc}}\right)$ as a function of temperature for all SBTZ compositions is illustrated in Fig. 9(c). The solid lines represents the linear fit to the data points, suggesting the Arrhenius like charge transport mechanism within the investigated temperature range. From this figure, it can be observed that the conductivity of all the specimens increased linearly with increasing temperature and the two regions are clearly identified with a change in slope around the dielectric anomalies. The activation energy values of conductivity were calculated according to the Arrhenius type conduction process:

$$
\sigma_{\mathrm{dc}}=\sigma_{\mathrm{o}} \mathrm{e}^{-E_{\mathrm{a}} / k_{\mathrm{B}} T}
$$

where $A$ is the pre-exponential factor, $E_{\mathrm{a}}$ is the activation energy, and $k_{\mathrm{B}}$ is the Boltzmann constant. In BLSF ceramics containing bismuth, it is well reported that oxygen vacancies $\left(\mathrm{V}_{\mathrm{O}}\right)$ can be easily created by bismuth volatilization at high temperature during sintering leading to creation of singly/doubly ionised oxygen vacancies $\left(\mathrm{V}_{\mathrm{O}}^{\prime}, \mathrm{V}_{\mathrm{O}}\right)$, ionisation of which creates conducting electrons as:

$$
\left.\begin{array}{l}
\mathrm{V}_{\mathrm{O}} \Leftrightarrow \mathrm{V}_{\mathrm{O}}^{\prime}+\mathrm{e}^{\prime} \\
\mathrm{V}_{\mathrm{O}}^{\prime} \Leftrightarrow \mathrm{V}_{\mathrm{O}}^{\prime \prime}+\mathrm{e}^{\prime}
\end{array}\right\}
$$

The conduction activation energies below $T_{\mathrm{C}}\left(E_{\mathrm{aI}}\right)$ lie in the range of $0.44 \mathrm{eV}$ to $0.75 \mathrm{eV}$ and above $T_{\mathrm{C}}\left(E_{\mathrm{aII}}\right)$ in the range of $0.59 \mathrm{eV}$ to $1.12 \mathrm{eV}$. A recent calculation suggests that the activation energy value for conduction are very close to the activation energy value of oxygen vacancies in layer perovskite ferroelectric oxides and the values are associated with $\mathrm{V}_{\mathrm{O}}^{\prime}$ and $\mathrm{V}_{\mathrm{O}}^{\prime \prime}$, respectively. ${ }^{23}$ At low temperatures, the $E_{\mathrm{aI}}$ values for SBZT indicate that the first ionization of oxygen vacancies and electron hopping are responsible for conduction because these $E_{\mathrm{a}}$ values are much less than that of the second-ionization of oxygen vacancies. ${ }^{41}$ At high temperatures, the $E_{\text {aII }}$ values increases, which shows that the electrical conduction is governed by the thermal excitation of carriers from the second ionization of oxygen vacancies. Thus, it can be concluded that the electrical conductivity is dominated by the oxygen vacancies migration, changing from a single to a doubly ionized mechanism around the ferroelectric phase transition. One of the conducting electrons is created by the oxygen vacancy ionization and the other from the $\mathrm{Ti}^{3+}$ and $\mathrm{Ti}^{4+}$ valence fluctuations. The created electrons would be trapped at defects, such as boundaries, dislocations, and lattice vacancies, and might hop between the neighbouring transition metal ions as $\mathrm{Ti}^{4+}$ and $\mathrm{Ti}^{3+}$. In addition, the low conductivity and high activation energy of the Z15 specimen indicate that the elimination of defects, trapped in the grain boundary and electrode-interface, significantly reduces the influence of domain pinning. In other words, the oxygen vacancies can easily be released out and no space charge is built up.

\subsection{Ferroelectric and piezoelectric properties}

Fig. 10 displays the polarization-electrical field (P-E) hysteresis loops of the SBTZ ceramics, which were recorded at room temperature with the maximum applied voltage of about $60 \mathrm{kV}$ $\mathrm{cm}^{-1}$. The parameters obtained from the hysteresis loop are listed in Table 2. It is observed that with increasing Zr-content, the $P_{\mathrm{r}}$ value decreases and the loop becomes slim. The $P_{\mathrm{r}}$ value is closely related to the orthorhombic distortion and the XRD results reveal that the orthorhombic distortion increases with increasing $\mathrm{Zr}$ content. Larger structural distortion generally leads to a large $P_{\mathrm{r}}$ value, which seems to contradict the current experimental results. However, it is noted that the hybridization between Ti-3d states and O-2p states decreases as $\mathrm{Zr}$ content increases, since the $\mathrm{Zr}^{4+}$ ion has a stronger metallicity than $\mathrm{Ti}^{4+}$, which tends to form ion bonds with $\mathrm{O}^{2-}$ easier. This may be the reason for the decrement of $P_{\mathrm{r}}$ value. Compared with previous reports about the polycrystalline zirconium-modified bismuth titanate (BTO) system, similar types of results were obtained, which may correlate with the present case. ${ }^{42}$ The variation of piezoelectric constant $\left(d_{33}\right)$ with $x$ for the SBTZ ceramics is listed in Table 2. The observed $d_{33}$ value increases linearly as $x$ increases up to $x \leq 0.15$ and giving a maximum value of $16 \mathrm{pC} / \mathrm{N}$ for the $x=0.15$ composition, then after it decreases drastically with increased $\mathrm{Zr}$ content. This suggests that after the substitutions of $\mathrm{Zr}^{4+}$, the ceramics become "softened", thus giving rise to significant improvements in the $d_{33}$ value, which makes the poling become more efficient because of less tangent loss. However, in Z20 and Z25 compositions, the loss of the sample increases due to secondary phases, which reduces the $d_{33}$ value. It is reported that the piezoelectric activity in ceramics can be enhanced to different degrees by constructing phase boundaries and modifying the microstructure of a material, while its piezoelectric activity is strongly sensitive to the phase boundary types. In this section, we further clarify the relationship between phase boundary and piezoelectric activity. It was proposed that the general grain growth observed in oxide-doped samples should be attributed to enhanced atomic mobility; dramatic grain growth can be induced by the difference in surface free energies between the grains. ${ }^{43}$ The enhancement in the grain size increases the $d_{33}$ values, but for higher concentrations $(x>0.15)$ as the secondary phase exists at the grain boundary the piezoelectric coefficient decreases. Again, the enhanced $d_{33}$ originates from the combined effects caused by the lattice distortion and the decreasing concentrations of oxygen vacancies.

The effect of the thermal annealing behaviour on the piezoelectric constant $\left(d_{33}\right)$ of the $\mathrm{Zr}$ modified specimens is shown in Fig. 11. The values of $d_{33}$ become almost constant up to the transition temperature and then decrease with increasing 


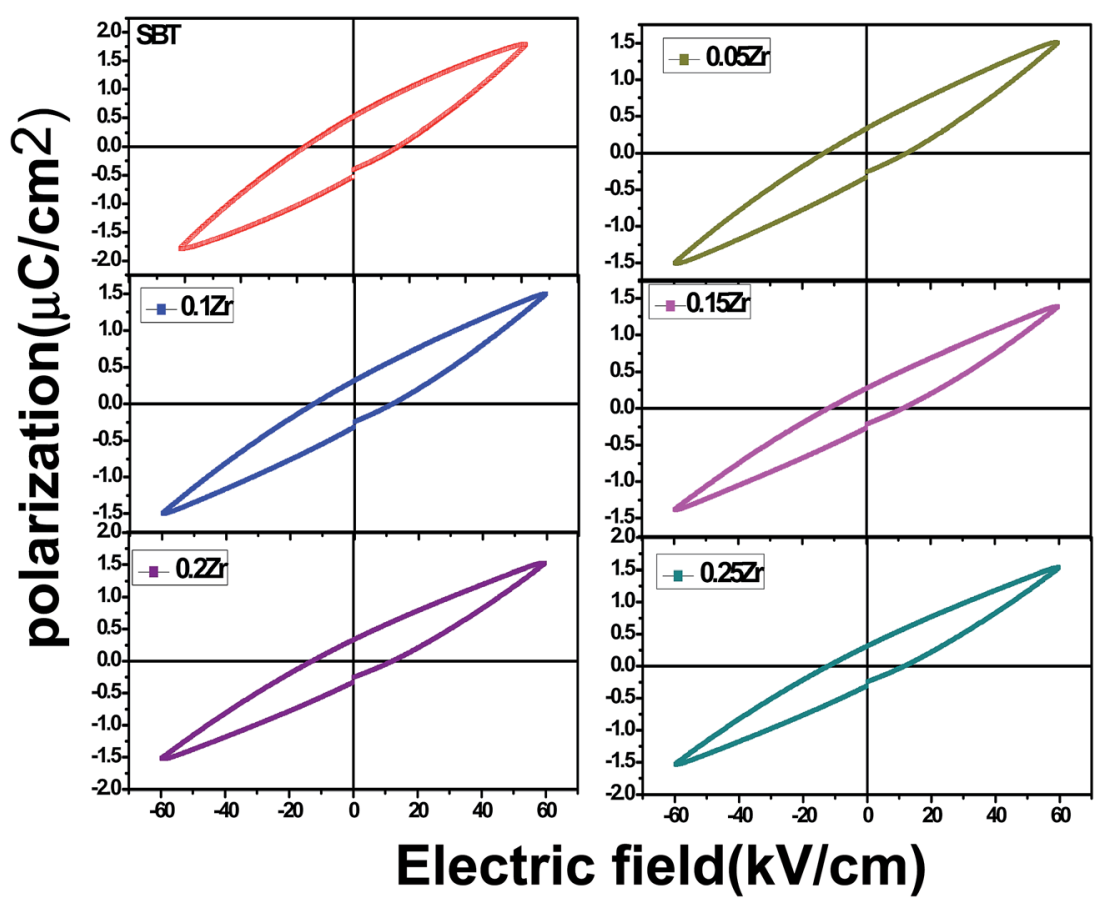

Fig. $10 \mathrm{P}-\mathrm{E}$ hysteresis loops of SBTZ ceramics at room temperature.

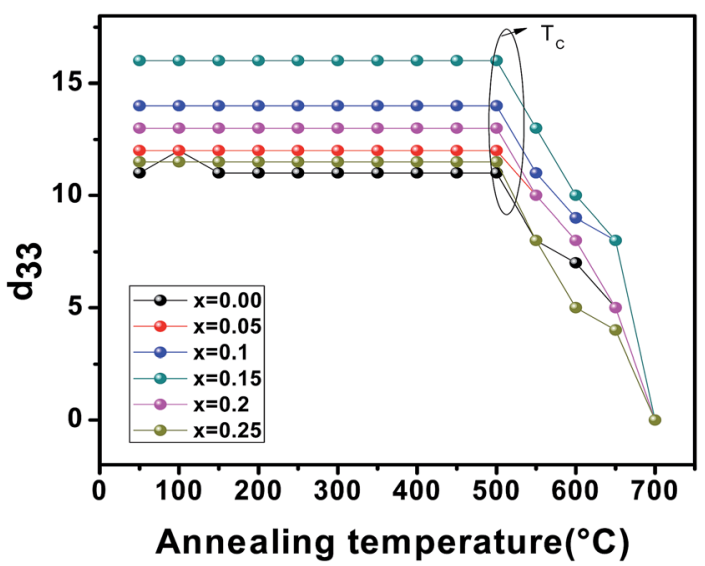

Fig. 11 Annealing temperature dependence of piezoelectric coefficient $\left(d_{33}\right)$ for SBTZ-x specimens.

temperature. This can be explained as the movement of non$180^{\circ}$ domain walls can produce a contribution to the piezoelectric property. ${ }^{44}$ Moreover, it shows that the piezoelectric constant $\left(d_{33}\right)$ of Z15 ceramic remains almost unchanged (16 $\mathrm{pC} / \mathrm{N}$ ) at temperatures below $550{ }^{\circ} \mathrm{C}$, indicating that the ceramic has excellent temperature stability so it is very tolerant to thermal annealing and might be an appropriate candidate for high-temperature applications.

\section{Conclusion}

It is concluded that B-site modification of SBT-based materials by zirconium was achieved using conventional solid-state processing. X-ray diffraction and Raman studies confirmed the formation of a single phase for $\mathrm{Zr}^{4+}$ substituted SBT up to $x \leq 0.15$ and for $x=0.2$ and $0.25(\mathrm{Z} 20, \mathrm{Z} 25)$ compositions, $\mathrm{ZrO}_{2}$ based impurity phases are detected. An increase in the grain size was observed due to $\mathrm{Zr}$ modification. The internal stresses developed within the SBTZ ceramics by substitution varies the transition temperature. The impedance spectroscopy analysis revealed that both grain and grain boundary are responsible for the conduction mechanism. The modification resulted in an increase in resistance of the material up to $x=0.15$ because of reduction of oxygen vacancies. AC conductivity analysis indicated that small and large polaron mechanisms take place in the $\mathrm{Zr}$-substituted SBT ceramic. The transport mechanism study revealed that the oxygen vacancies are mainly responsible for the conduction. The decrement of the $P_{\mathrm{r}}$ value in the $\mathrm{Zr}$-modified samples is due to the stronger metallicity of the $\mathrm{Zr}^{4+}$ ion compared to $\mathrm{Ti}^{4+}$. Among all the compositions, $x=0.15$ showed enhanced ferroelectric and piezoelectric properties, so could be suitable for hightemperature piezoelectric applications.

\section{Acknowledgements}

One of the authors (Priyambada Nayak) acknowledges the Department of Science and Technology, India (Reference number SR/WOS-A/PM-1003/2014(G)) for providing financial support.

\section{References}

$1 \mathrm{H}$. kodama, F. izumi and A. watanabe, New Members of a Family of Layered Bismuth Compounds, J. Solid State Chem., 1981, 36, 349-355.

2 E. C. Subbarao, ferroelectricity in $\mathrm{Bi}_{4} \mathrm{Ti}_{3} \mathrm{O}_{12}$ and its solid solutions, Phys. Rev., 1961, 122, 804-807. 
3 A. P. Araujo, J. D. Cuchiaro, L. D. McMillan, M. C. Scott and J. F. Scott, Nature, 1995, 374, 627.

4 I. M. Reaney and D. Damjanovic, Crystal structure and domain-wall contributions to the piezoelectric properties of strontium bismuth titanate ceramics, J. Appl. Phys., 1996, 80(7), 4223-4225.

5 A. R. James, Effect of oxygen assisted sintering on piezoelectric properties of $\mathrm{SrBi}_{4} \mathrm{Ti}_{4} \mathrm{O}_{15}$ ceramics prepared via high energy mechano chemical processing, Ceram. Int., 2015, 41, 5100-5106.

6 Y. P. Chen, Y. Y. Yao, Z. H. Bao, P. Bao, J. S. Zhu and Y. N. Wang, Study on ferroelectric and dielectric properties of La-doped $\mathrm{SrBi}_{4} \mathrm{Ti}_{4} \mathrm{O}_{15}$ ceramics, Mater. Lett., 2003, 57, 3623-3628.

7 B. Mamatha and P. Sarah, Effect of dysprosium substitution on electrical properties of $\mathrm{SrBi}_{4} \mathrm{Ti}_{4} \mathrm{O}_{15}$, Mater. Chem. Phys., 2014, 147, 375-381.

8 D. Peng, H. Zou, C. Xu, X. Wang, X. Yao, J. Lin and T. Sun, Upconversion luminescence, ferroelectrics and piezoelectrics of Er Doped $\mathrm{SrBi}_{4} \mathrm{Ti}_{4} \mathrm{O}_{15}$, AIP Adv., 2012, 110, 042187.

9 P. Nayak, S. R. Mohapatra, P. Kumar and S. Panigrahi, Effect of $\mathrm{Ba}^{2+}$ substitution on the structural and electrical properties of $\mathrm{SrBi}_{4} \mathrm{Ti}_{4} \mathrm{O}_{15}$ ceramic, Ceram. Int., 2015, 41, 9361-9372.

10 H. Hao, H. Liu and S. Ouyang, Structure and ferroelectric property of Nb-doped $\mathrm{SrBi}_{4} \mathrm{Ti}_{4} \mathrm{O}_{15}$ ceramics, J. Electroceram., 2009, 22, 357-362.

11 J. Zhu, X. Y. Mao and X. B. Chen, Properties of vanadiumdoped $\mathrm{SrBi}_{4} \mathrm{Ti}_{4} \mathrm{O}_{15}$ ferroelectric ceramics, Solid State Commun., 2004, 129, 707-710.

12 P. Nayak, T. Badapanda and S. Panigrahi, Dielectric, ferroelectric and conduction behaviour of tungsten modified $\mathrm{SrBi}_{4} \mathrm{Ti}_{4} \mathrm{O} 15$ ceramic, J. Mater. Sci.: Mater. Electron., 2016, 27, 1217-1226.

13 M. Aghayana, A. Khors, M. Behdania and A. M. Hashimc, Sol-gel combustion synthesis of Zr-doped $\mathrm{BaTiO}_{3}$ nanopowders and ceramics: Dielectric and ferroelectric studies, Ceram. Int., 2014, 40, 16141-16146.

14 A. Ulcinas, M. Es-Souni and V. Snitka, Investigation of microstructure and piezoelectric properties of $\mathrm{Zr}-$ and $\mathrm{Sm}$ doped $\mathrm{PbTiO}_{3}$ nanostructured thin films derived by sol-gel technology, Sens. Actuators, B, 2005, 109, 97-101.

15 J. Chen, Q. Yun, W. Gao, Y. Bai, C. Nie and S. Zhao, Improved ferroelectric and fatigue properties in $\mathrm{Zr}$ doped $\mathrm{Bi}_{4} \mathrm{Ti}_{3} \mathrm{O}_{12}$ thin films, Mater. Lett., 2014, 136, 11-14.

16 A. Chakrabarti and J. Bera, Structure and relaxor behaviour of $\mathrm{BaBi}_{4} \mathrm{Ti}_{4-x} \mathrm{Zr}_{x} \mathrm{O}_{15}$ ceramics, Curr. Appl. Phys., 2010, 10, 574-579.

17 D. Hennings, A. Schnell and G. Simon, Diffuse Ferroelectric Phase Transitions in $\mathrm{Ba}\left(\mathrm{Ti}_{1-y} \mathrm{Zr}_{y}\right) \mathrm{O}_{3}$ Ceramics, J. Am. Ceram. Soc., 2006, 65(11), 539-544.

18 S. Jesurani, S. Kanagesan, M. Hashim and I. Ismail, Dielectric properties of $\mathrm{Zr}$ doped $\mathrm{CaCu}_{3} \mathrm{Ti}_{4} \mathrm{O}_{12}$ synthesized by sol-gel route, J. Alloys Compd., 2013, 551, 456-462.

19 S. K. Rout, A. Hussian, J. S. Lee, I. W. Kim and S. I. Woo, Impedance spectroscopy and morphology of $\mathrm{SrBi}_{4} \mathrm{Ti}_{4} \mathrm{O}_{15}$ ceramics prepared by soft chemical method, J. Alloys Compd., 2009, 477, 706-711.

20 E. V. Ramana, M. P. F. Graça, M. A. Valente and T. Bhima Sankaram, Improved ferroelectric and pyroelectric properties of $\mathrm{Pb}$-doped $\mathrm{SrBi}_{4} \mathrm{Ti}_{4} \mathrm{O}_{15}$ ceramics for high temperature applications, J. Alloys Compd., 2014, 583, 198205.

21 E. C. Subbarao, J. Chem. Phys., 1961, 34, 695-696.

22 C. Hervoches, A. Snedden, R. Riggs, S. H. Kilcoyne, P. Manuel and P. Lightfoot, Structural Behavior of the Four-Layer Aurivillius-Phase Ferroelectrics $\mathrm{SrBi}_{4} \mathrm{Ti}_{4} \mathrm{O}_{15}$ and $\mathrm{Bi}_{5} \mathrm{Ti}_{3} \mathrm{FeO}_{15}$, J. Solid State Chem., 2002, 164, 280-291.

$23 \mathrm{~F}$. Rehman, H. Jin and J. Li, Effect of reduction/oxidation annealing on the dielectric relaxation and electrical properties of Aurivillius $\mathrm{Na}_{0.5} \mathrm{Gd}_{0.5} \mathrm{Bi}_{4} \mathrm{Ti}_{4} \mathrm{O}_{15}$ ceramics, $R S C$ Adv., 2016, 6, 35102.

24 A. l. Abassi, N. Kallel, S. Kallel, K. Khirouni and O. Peña, Electrical conductivity and complex impedance analysis of $\mathrm{La}_{0.7-x} \mathrm{Nd}_{x} \mathrm{Sr}_{0.3} \mathrm{Mn}_{0.7} \mathrm{Ti}_{0.3} \mathrm{O}_{3}(x<0.30)$ Perovskite, J. Magn. Magn. Mater., 2016, 401, 853-859.

25 H. Hao, H. X. Liu, M. H. Cao, X. M. Min and S. X. Ouyang, Study of A-site doping of $\mathrm{SrBi}_{4} \mathrm{Ti}_{4} \mathrm{O}_{15}$ Bi-layered compounds using micro-Raman spectroscopy, Appl. Phys. A, 2006, 85, 69-73.

26 J. Zhu, X. B. Chen, J. H. He and J. C. Shen, Raman scattering investigations on lanthanum-doped $\mathrm{Bi}_{4} \mathrm{Ti}_{3} \mathrm{O}_{12}-\mathrm{SrBi}_{4} \mathrm{Ti}_{4} \mathrm{O}_{15}$ intergrowth ferroelectrics, J. Solid State Chem., 2005, 178, 2832-2837.

27 K. W. Kwok and H. Y. Wong, Piezoelectric and pyroelectric properties of $\mathrm{Cu}$-doped $\mathrm{CaBi}_{4} \mathrm{Ti}_{4} \mathrm{O}_{15}$ lead-free ferroelectric ceramics, J. Phys. D: Appl. Phys., 2009, 42, 0954191-0954195.

28 C. L. Du, S. T. Zhang, G. X. Cheng, M. H. Lu, Z. B. Gu, J. Wang and Y. F. Chen, Composition-dependent structures and properties of $\mathrm{Bi}_{4} \mathrm{Ti}_{3-x} \mathrm{Zr}_{x} \mathrm{O}_{12}$ ceramics, Phys. B, 2005, 368, 157-162.

29 P. K. Patel, K. L. Yadav, H. Singh and A. K. Yadav, Origin of giant dielectric constant and magnetodielectric study in $\mathrm{Ba}\left(\mathrm{Fe}_{0.5} \mathrm{Nb}_{0.5}\right) \mathrm{O}_{3}$ nanoceramics, J. Alloys Compd., 2014, 591, 224-229.

30 O. Raymond, Frequency-temperature response of ferroelectromagnetic $\mathrm{PbFe}_{1 / 2} \mathrm{Nb}_{1 / 2} \mathrm{O}_{3}$ ceramics obtained by different precursors. Part II. Impedance spectroscopy characterization, J. Appl. Phys., 2005, 97, 084108, 1-8.

31 C. Long, H. Fan, M. Li, P. Ren and Y. Cai, candidate for leadfree ultrahigh-temperature piezoelectrics: the excellent electro-mechanical properties of Aurivillius oxides, $\mathrm{Ca}_{1-5 x} \mathrm{Li}_{2 x} \mathrm{Nd}_{2 x-x} \mathrm{Bi}_{2} \mathrm{Nb}_{2-2 x} \mathrm{Sc}_{x} \mathrm{~W}_{x} \mathrm{O}_{9-1.5 x}$, CrystEngComm, 2013, 15, 10212.

32 M. Sindhu, N. Ahlawat, S. Sanghi, A. Agarwal, R. Dahiya and N. N. Ahlawat, Rietveld refinement and impedance spectroscopy of calcium titanate, Curr. Appl. Phys., 2012, 12, 1429-1435.

33 E. J. Abram and D. C. Sinclair, A Strategy for Analysis and Modelling of Impedance Spectroscopy Data of Electroceramics: Doped Lanthanum Gallate, $J$. Electroceram., 2003, 10, 165-177. 
34 D. Mancic, V. Paunovic, M. Vijatovic, B. Stojanovic and L. Zivkovic, Electrical Characterization and Impedance Response of Lanthanum Doped Barium Titanate Ceramics, Sci. Sintering, 2008, 40, 283-294.

35 C. E. Ciomaga, M. T. Buscaglia, V. Buscaglia and L. Mitoseriu, Oxygen deficiency and grain boundary-related giant relaxation in $\mathrm{Ba}(\mathrm{Zr}, \mathrm{Ti}) \mathrm{O}_{3}$ ceramics, J. Appl. Phys., 2011, 110, 114110.

36 A. Pelaiz-Barranco, Dielectric relaxation and electrical conductivity in ferroelectric ceramic/polymer composites around the glass transition, Appl. Phys. Lett., 2012, 100, 212903.

37 M. Sindhu, N. Ahlawat, S. Sanghi, R. Kumari and A. Agarwal, Effect of $\mathrm{Zr}$ substitution on phase transformation and dielectric properties of $\mathrm{Ba}_{0.9} \mathrm{Ca}_{0.1} \mathrm{TiO}_{3}$ ceramics, J. Appl. Phys., 2013, 114, 164106.

38 I. Coondoo, A. K. Jha and S. K. Agarwal, Enhancement of dielectric characteristics in donor doped Aurivillius $\mathrm{SrBi}_{2} \mathrm{Ta}_{2} \mathrm{O}_{9}$ ferroelectric ceramics, J. Eur. Ceram. Soc., 2007, 27, 253-260.

39 A. Singh, K. Amarnath, K. Prasad and A. Prasad, Impedance, Electrical Conductivity and Piezoelectric Studies on $\mathrm{Nb}^{5+}$ doped $\left(\mathrm{Bi}_{0.5} \mathrm{Na}_{0.5}\right)_{0.94} \mathrm{Ba}_{0.06} \mathrm{TiO}_{3}-\mathrm{PVDF}_{0-3}$ composites, IOSR Journal of Applied Physics, 2015, 7, 17-26.

40 H. M. Usama, A. Sharif, M. A. Zubair, M. A. Gafur and S. M. Hoque, Structural transition and its effect in $\mathrm{La}, \mathrm{Zr}$ co-substituted mono-domain $\mathrm{BiFeO}_{3}$, J. Appl. Phys., 2016, 120, 214106.

$41 \mathrm{~J}$. Wu and J. Wang, Ferroelectric and Impedance Behavior of La- and Ti-Co doped $\mathrm{BiFeO}_{3}$ Thin Films, J. Am. Ceram. Soc., 2010, 93(9), 2795-2803.

42 O. Subohi, G. S. Kumar, M. M. Malik and R. Kurchania, Effect of B-site isovalent doping on electrical and ferroelectric properties of lead free bismuth titanate ceramics, J. Phys. Chem. Solids, 2016, 93, 91-99.

43 J. Wu, D. Xiao and J. Zhu, Potassium-Sodium Niobate LeadFree Piezoelectric Materials: Past, Present, and Future of Phase Boundaries, Chem. Rev., 2015, 115(7), 2559-2595.

44 C. Long and H. Fan, Effect of lanthanum substitution at A site on structure and enhanced properties of new Aurivillius oxide $\mathrm{K}_{0.25} \mathrm{Na}_{0.25} \mathrm{La}_{0.5} \mathrm{Bi}_{2} \mathrm{Nb}_{2} \mathrm{O}_{9}$, Dalton Trans., 2012, 41, 11046. 